\title{
A New Approach for Environmental Modelling of LULC Changes in Semi- arid Regions of Anantapur District, Andhra Pradesh, India Using Geospatial Techniques
}

\author{
B. Pradeep Kumar*, K. Raghu Babu*†, P. Padma Sree**, M. Rajasekhar* and M. Ramachandra* \\ *Department of Geology, Yogi Vemana University, Kadapa, Andhra Pradesh, India \\ **Department of Geology, Government College (A), Anantapur, Andhra Pradesh, India \\ $\dagger$ Corresponding author: K. Raghu Babu; dr.kraghu@gmail.com
}

Nat. Env. \& Poll. Tech.

Website: www.neptjournal.com

Received: 04-05-2020

Revised: 23-07-2020

Accepted: 27-08-2020

Key Words:

LULC

Satellite data

NDVI

Ecosystem degradation

Remote Sensing and GIS

\begin{abstract}
This study aims to define the changing pattern of land use and its geo-environmental impacts on the semi-arid region of Anantapur district of AP state, India. Satellite imageries were analysed to perceive the variations in land use and land cover in the past 9 years from 2010 to 2019. RS and GIS modelling has helped in the mapping of land use and land cover changes. The study has assumed five characteristic features, they are (i) Waterbodies, (ii) Vegetation, (iii) Fallow land, (iv) Cultivation lands, and (v) Degraded lands. The results reveal that, from 2010 to 2019, there is a decrease in water bodies, vegetation and fallow lands of $6.75 \mathrm{~km}^{2}, 42.96 \mathrm{~km}^{2}$ and $105.45 \mathrm{~km}^{2}$ respectively. While cultivation lands and degraded lands increased to $4.7 \mathrm{~km}^{2}$ and $105.45 \mathrm{~km}^{2}$ respectively. The environmental ecosystem is disturbed due to the increase in degraded lands, thus making the study area turn into a desert. Normalized Differential Vegetation Index (NDVI) and Soil Adjusted Vegetation Index (SAVI) are very useful for the accuracy assessment of vegetation, cultivation land and waterbodies in this LULC change detection studies.
\end{abstract}

\section{INTRODUCTION}

Geo-environment, not only from the environmental point of view but also in relative social pecuniary aspect has a specific perception in the human life. The role of the geo-environment in the aforesaid aspects has been undervalued and we are still far from exploiting it to its full extent. An empathetic of the possessions of the Earth's resources and their undercurrents is vital for unravelling difficulties in fluctuating fields, such as soil, air, water contamination, soil destruction, waste disposal and construction provisions and foundations (Senthil 2013, Badapalli et al. 2019). Empathetic geological and geomorphological processes are also important to other parts of the study including the progression and alleviation of natural and man persuaded threats and jeopardizes, land protection and renovation, landscape and urban planning, ecosystem inventories and natural heritage assessments (Chao et al. 2004, Rawat et al. 2013).

Land Use and Land Cover (LULC) are often blended. This is somewhat logical for the reason that both terms are scarcely related and to more or less scope even overlap. In this normal state, land cover systematizes a flawless arrival of the environmental equilibrium among parent rock, climatic ailment, soil, and vegetation. Landcover eminent in various categories i.e., area of vegetation, bare soil, rock outcrops, wet and water bodies etc. in simple terms land cover is the result of observation. Land use denotes land cover but differs in relations to its socio-economic persistence and global use (Harshika \& Sopan 2012). This is in pure contrast with land cover as stated above which is most expressive and deals with physical observations. Land use may differ in nature and intensity, with the purpose it dealt with during the physical observations (Dewan et al. 2009, Anees et al. 2014, Kumar et al. 2020). Land use varies from land cover for the reason intentional on and role of people to familiarize the natural land cover to their assistances.

Geographical Information System (GIS) epitomizes a commanding set of tools for gathering, filament, recovering and presenting spatial data from the real world. Remote Sensing (RS) from airborne and spaceborne platforms delivers appreciated data for mapping, geo-environmental monitoring (Babu et al. 2012). The incorporation of RS and GIS modelling technologies in the field of environmental protection is inevitable and assists in decision making.

\section{STUDY AREA}

The present study region falls under semi-arid provinces of Anantapur district (13 $40^{\prime}$ and $15^{\circ} 15^{\prime}$ Northern latitude and $76^{\circ} 50^{\prime}$ and $78^{\circ} 30^{\prime}$ Eastern longitude) which falls within 
the rain shadow range of Western Ghats, in the interior of Deccan Plateau (Fig. 1). The district is circumscribed by Kurnool District in the north Kadapa District in the northeast, Chittoor District in the south-east, and Karnataka State in the West. Two main rivers flows over the study region, one is Hagari/Vedavathi and another one is Penna River. There are two seasons in the study region, they are South-west monsoon (June-September), and the North-east monsoon (October to December). Hot weather from March to May and the cold period from January to February.

\section{DATA AND METHODOLOGY}

\section{Data Acquired}

1. SOI (Survey of India) topo sheet no. 57F/1, 57F/2, $57 \mathrm{~F} / 5,57 \mathrm{~F} / 6,57 \mathrm{~B} / 13$ and 57B/14.

2. Landsat imageries of three dissimilar periods i.e.,2010 and 2019 have taken freely from USGS earth explorer site (http://earthexplorer.usgs.gov/) and from NRSC site (http://bhuvan.nrsc.gov.in). with the resolution of 30m and 15m, datum WGS 1984 and UTM zone 44N.

\section{Software Used}

1. ERDAS imagine 2014

2. ArcGIS

\section{Methodology}

The data sets were improved in ERDAS Imagine 2014, satellite image processing software to create a false colour composite (FCC). The layer stack option in the image interpreter toolbox was used to generate FCCs for the study regions. The sub-setting of satellite images were performed for extracting study region from both images by taking geo-referenced outline boundary for better classification of LULC through Unsupervised option, NDVI and SAVI were also adopted to assess the vegetation and water bodies in the classification.

\section{RESULTS AND DISCUSSION}

\section{LULC Change Detection and Analysis}

For the execution of LULC change detection, a supervised classification method was engaged. A pixel-based evaluation was cast-off to collect the transformation info on pixel base and hence, infer the variations more precisely. Classified image pairs of the two-fold dissimilar period (2010 to 2019) information are linked by means of cross-tabulation in order to determine qualitative and quantifiable variation features. A change matrix (Babu et al. 2012, Kumar et al. 2018 \& 2019, Rajasekhar et al. 2019) was shaped with the help of ERDAS imagine 2014 software. Measurable extent data of the complete LULC variations as well as increases and upset in apiece category between 2010 and 2019 were compiled.

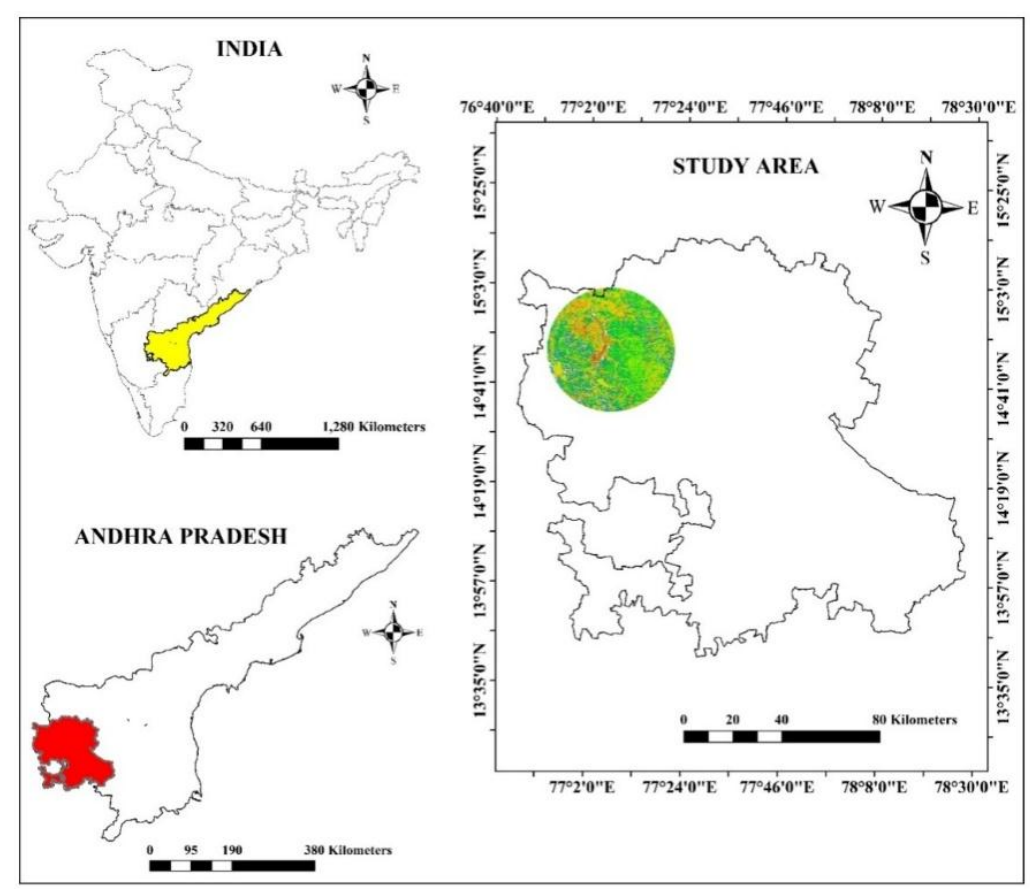

Fig. 1: Location map. 


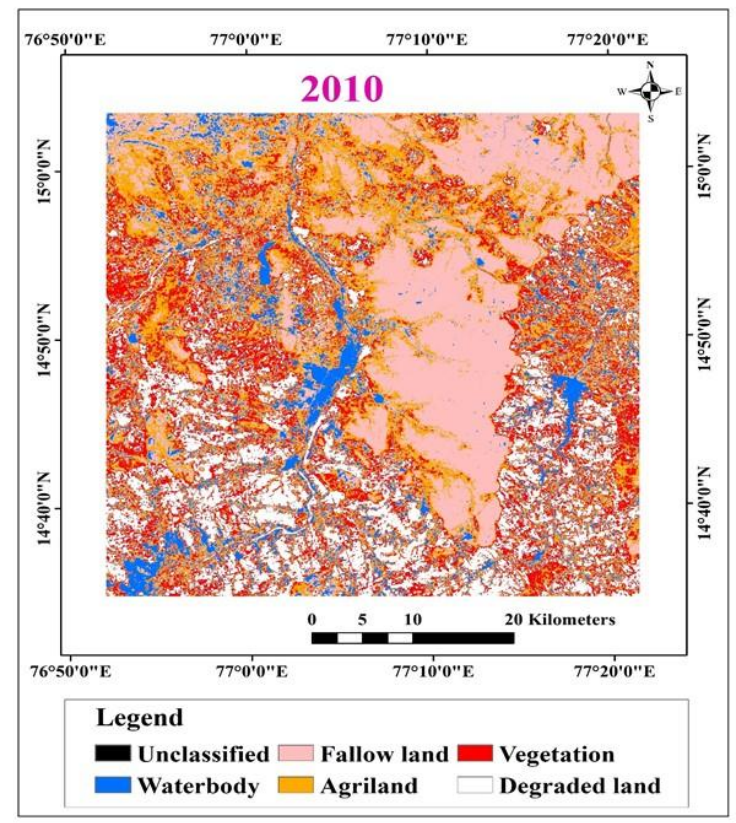

Fig. 2: 2010 LULC

\section{Accuracy Assessment of LULC Using NDVI and SAVI}

NDVI and SAVI techniques have been adopted for the accuracy assessment of vegetation, cultivation land, and waterbodies existing in the study region examination for the LULC change detection. NDVI is involved in the examination of vegetation and cultivation land, and SAVI for

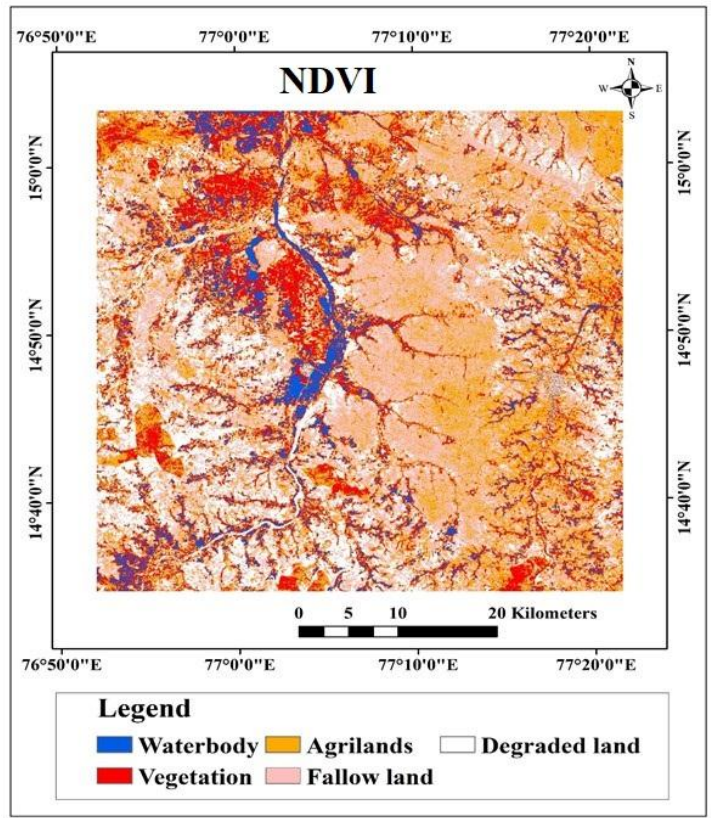

Fig. 4: NDVI

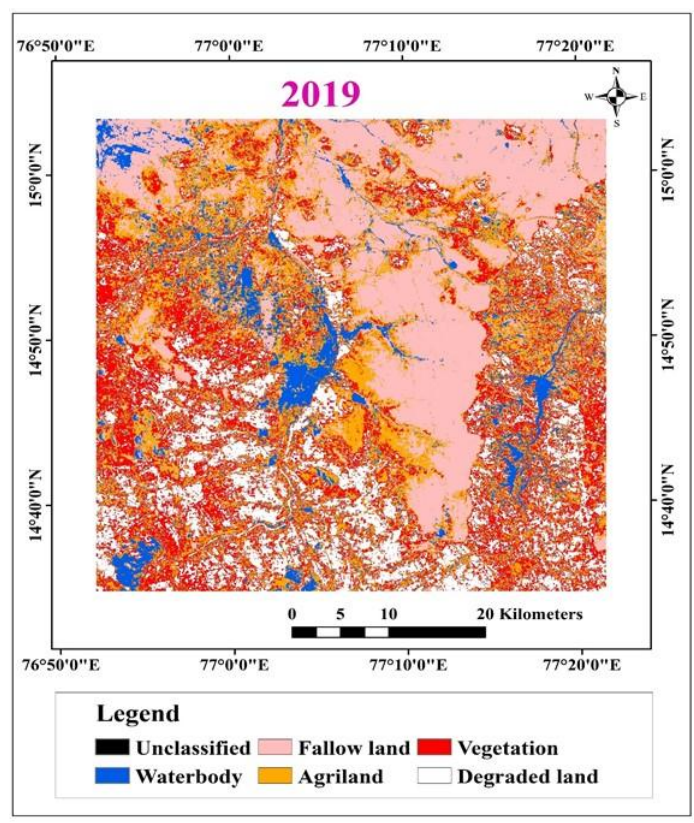

Fig. 3: 2019 LULC

water bodies assessment. Both the techniques were used to assess, whether vegetation, cultivation land and waterbodies extended in the unsupervised classification are identical to the NDVI and SAVI categorized areas or not. Fig. 4 and Fig. 5 depict the NDVI and SAVI respectively. The results revealed that both the unsupervised and NDVI, SAVI are almost the same.

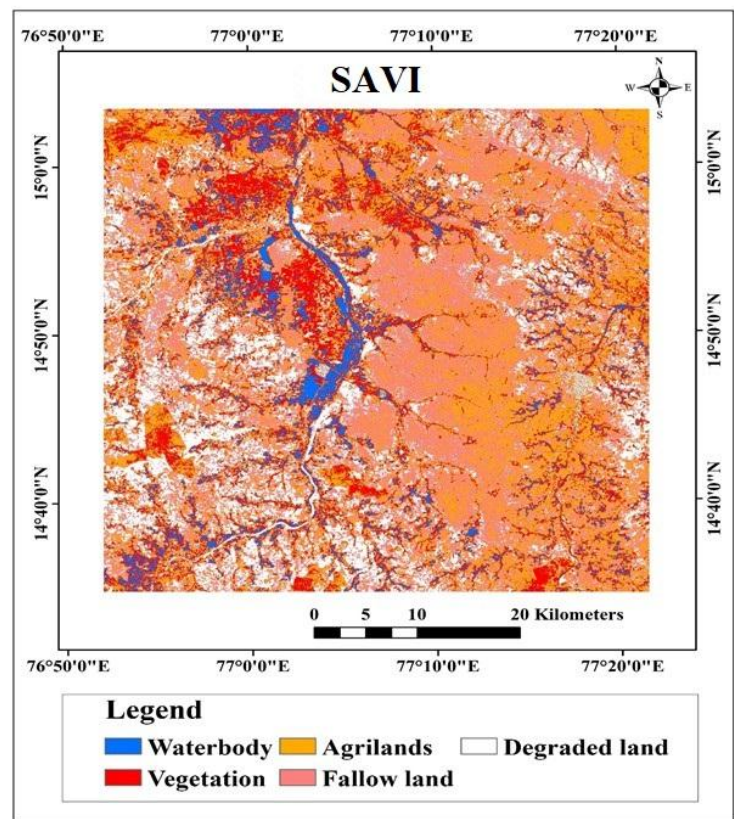

Fig. 5: SAVI 


\section{NDVI}

Established on the values of NDVI and in relation to the Google Earth imageries to classify and enumerate the vegetation change during the period of 2010 and 2019 (Fig. 2 and Fig. 3), have been applied to five classes i.e., Waterbody, Vegetation, Cultivation land, Fallow land, and Degraded lands. This was carried out in ERDAS imagine 2014, with the formula or combination of bands given below.

NDVI = (near-infrared (NIR) band - RED band $)$ /(near-infrared (NIR) band + RED band)

near-infrared (NIR) band and the RED band are the reflectance radiated in the NIR band 7 and the visible red $5(0.8$ $1.1 \mu \mathrm{m}$ and 0.6-0.7 $\mu \mathrm{m}$ ) waveband of the Land sat 8. The procedure of the NDVI in the ERDAS imagine software is shown in Fig. 6.

\section{SAVI}

In the present study, the computed SAVI is used to evaluate the variations in surface porousness between 2010 and
2019. Usually, SAVI specifies waterbody, vegetation, and cultivation exposure and health with respect to saturation, soil colour, and moisture therefore accounts for the high inconsistency areas. SAVI correspondingly controls the influence of soil brightness in NDVI and thus, minimizes soil brightness related noise in vegetation coverage estimation. Since coverage, brightness, and health of vegetation are strappingly related to surface permeability, SAVI delivers a significant proxy for the identification of impermeable surfaces. Calculations of SAVI could be done through the formula.

$$
\mathrm{SAVI}=((\mathrm{NIR}-\mathrm{RED}) /(\mathrm{NIR}+\mathrm{RED}+\mathrm{L})) *(1+\mathrm{L})
$$

Where RED is the reflectance of band 3 and NIR is the reflectance value of the near-infrared band (Band 4). $\mathrm{L}$ is the soil brightness correction factor. For dense vegetation and highly permeable surface areas, $\mathrm{L}=0$ and for vegetation scarce and impermeable surface areas, $\mathrm{L}=1$. The procedure of the SAVI in the ERDAS imagine software is shown in Fig. 7.

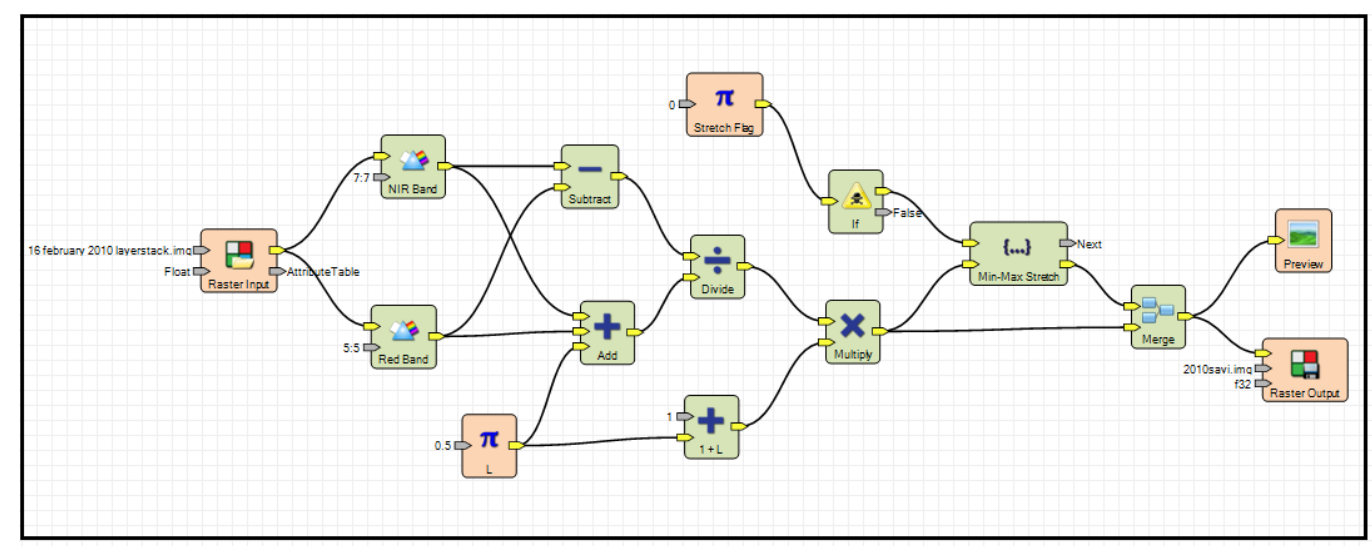

Fig. 6: NDVI bands in ERDAS imagine software.

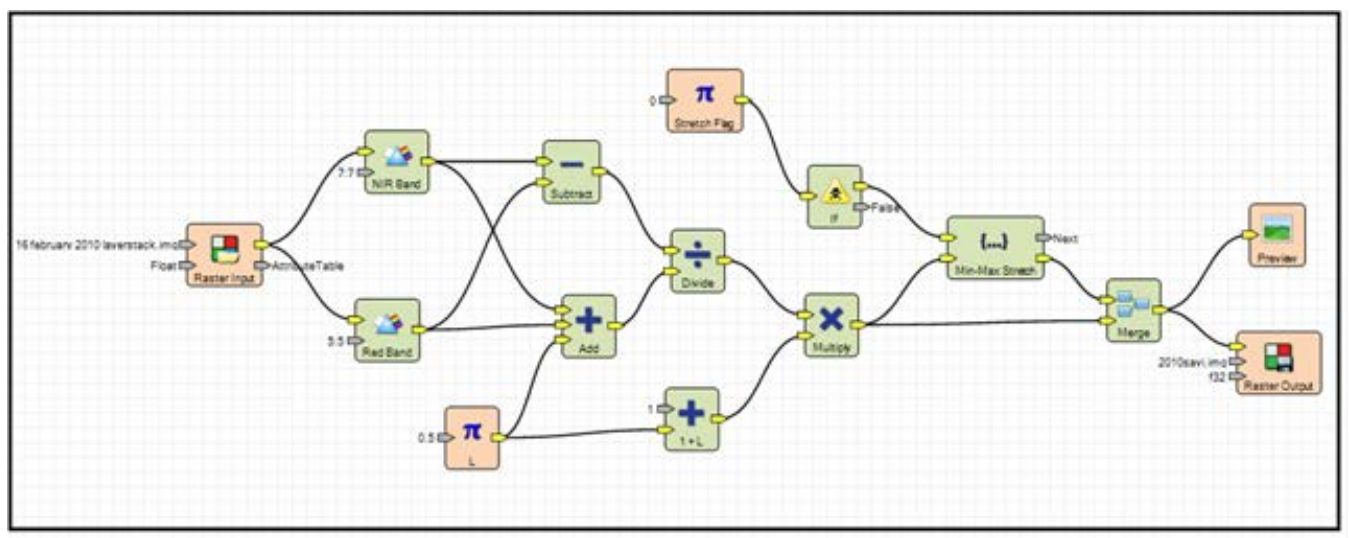

Fig. 7: SAVI bands in ERDAS imagine software. 
Table 1: statistical calculation.

\begin{tabular}{|c|c|c|c|c|c|c|}
\hline \multirow[t]{2}{*}{ LULC categories } & \multicolumn{2}{|l|}{2010} & \multicolumn{2}{|l|}{2019} & \multicolumn{2}{|c|}{ Changes from 2000-2019 } \\
\hline & $\mathrm{km}^{2}$ & Percentage $\%$ & $\mathrm{~km}^{2}$ & Percentage & $\mathrm{km}^{2}$ & Percentage \\
\hline waterbody & 207.06 & 7.43 & 200.31 & 7.18 & -6.75 & -0.25 \\
\hline Vegetation & 793.92 & 28.49 & 750.96 & 26.95 & -42.96 & -1.54 \\
\hline Agri land & 671.07 & 24.08 & 675.77 & 24.25 & 4.70 & 0.17 \\
\hline Fallow land & 589.24 & 21.14 & 483.79 & 17.36 & -105.45 & -3.78 \\
\hline \multirow[t]{2}{*}{ Degraded land } & 524.94 & 18.84 & 675.40 & 24.24 & 150.46 & 5.40 \\
\hline & $2,786.23$ & 100 & $2,786.23$ & 100 & & \\
\hline
\end{tabular}

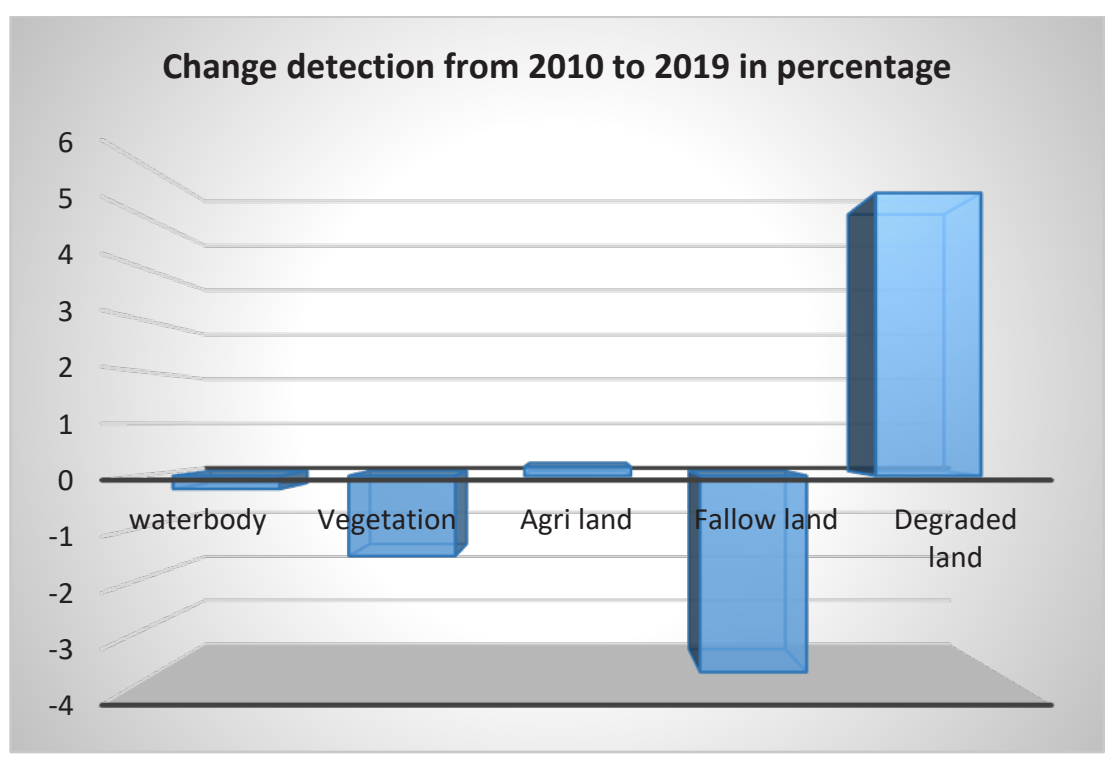

Fig. 8: Change detection from 2010 to 2019.

\section{LULC Status}

LULC classification results obtained from 2010 to 2019 were shown in Table 1. Waterbody has calculated as 207.06 $\mathrm{km}^{2}$ in the year 2010 and it is decreased to $200.31 \mathrm{~km}^{2}$ in the year 2019. Vegetation is calculated as $793.92 \mathrm{~km}^{2}$ in the year 2010 and it is decreased to $750.96 \mathrm{~km}^{2}$ in the year 2019. There is little increase in Cultivation land, i.e., 671.07 $\mathrm{km}^{2}$ in the year 2010 and in the year 2019 it is increased to $675.77 \mathrm{~km}^{2}$. Fallow land and is calculated as $589.24 \mathrm{~km}^{2}$ in the year 2010 and it is decreased to $483.79 \mathrm{~km}^{2}$ in the year 2019. Degraded land is increased at alarming rates and it is calculated as $524.94 \mathrm{~km}^{2}$ in the year 2010 and it is increased to $675.40 \mathrm{~km}^{2}$ in the year 2019. Fig. 8 shows the graphical representation of LULC and its impact on geo-environmental changes in the percentage during the decade, i.e. 2000 to 2019.

\section{CONCLUSION}

This study evaluated land use patterns, major improvement activities and environmental influences of land-use change in the study region over the past 9 years using an integrated method of Remote Sensing and GIS modelling. Fallouts evidently reveal that LULC variations were significant throughout the period from 2010 to 2019 . There is a negative sign in certain factors like the decrease in waterbodies is noticed $(0.25 \%)$ there also a prominent decrease in vegetation, fallow land ( $1.54 \%$ and $3.78 \%$ respectively). Positive sign observed in Cultivation land with an increase of $0.17 \%$. Degraded land is increased at an alarming rate (5.4\%) and it is a negative sign for the environmental ecosystem immanence. Most of the people living in these villages are getting migrated to other villages or towns for their livelihood. This may lead to an environmental ecosystem imbalance. Our results clearly reveal this severe condition through the NDVI and SAVI in relation to that of the unsupervised classification studies. Geospatial techniques like RS and GIS provide pointers on tools to monitor, approximation, appraise and achieve supervisory factors on the environmental imperils to save the life and the society. 


\section{ACKNOWLEDGEMENT}

B. Pradeep Kumar, greatly thankful to the Department of Science and Technology (DST), Government of India, for financial support through Inspire programme (Sanction order No. DST/INSPIRE Fellowship/2017/IF170114). Also thankful to USGS for remote sensing data utilization, Department of Geology, Yogi Vemana University, for necessary facilities for carrying out the research work.

\section{REFERENCES}

Anees, M. T., Javed, A. and Khanday, M. Y. 2014. Spatio-temporal land cover analysis in Makhawan Watershed (MP), India through remote sensing and GIS techniques. Journal of Geographic Information System, 6(4): 298-306.

Babu, K. R. and Raju, G. S. 2012. Application of remote sensing for delineation of uranium bearing Vempalli dolomites in and around Tummalapalli area, Cuddapah Basin, India. International Journal of Geomatics and Geosciences, 2(3): 842-852.

Badapalli, P. K., Raghu Babu, K., Rajasekhar, M. and Ramachandra, M. 2019. Assessment of aeolian desertification near Vedavathi river channel in Central part of Andhra Pradesh: Remote Sensing Approach, Remote Sensing of Land, 3(1): 39-49.

Chao, H.A.N. 2004. Some research advances and methods on detecting land cover change by remote sensing. Journal of Arid Meteorology, 22(2): 76-81.

Dewan, M. Ashraf, Yamaguchi Yasushi, 2009. Land use and land cover change in Greater Dhaka, Bangladesh using remote sensing to promote sustainable urbanization. Applied Geography Journal, 29: 390-401.

Harshika and Sopan I. 2012. Land use land cover classification and change detection using high resolution temporal satellite data. Journal of Environment, 1(4): 146-15.

Kumar, B. P., Babu, K. R., Rajasekhar, M. and Ramachandra, M. 2019. Assessment of land degradation and desertification due to migration of sand and sand dunes in Beluguppa Mandal of Anantapur district (AP, India), using remote sensing and GIS techniques. J. Ind. Geophys. Union, 23(2): 173-180.

Kumar, B. P., Raghu Babu, K., Rajasekhar, M., Narayana Swamy, B. and Ramachandra, M. 2019. Landuse/landcover changes and geo-environmental impacts on Beluguppa Mandal of Anantapur District of Andhra Pradesh, India, using remote sensing and GIS modelling. Research \& Reviews: Journal of Space Science \& Technology, 8(2): 6-15.

Kumar, B.P., Babu, K.R., Rajasekhar, M. et al. 2020. Identification of land degradation hotspots in semiarid region of Anantapur district, Southern India, using geospatial modelling approaches. Model. Earth Syst. Environ. 6: 1841-1852. https://doi.org/10.1007/s40808-020-00794-x.

Rajasekhar, M., Raju, G.S. and Raju, R.S. 2019. Data on artificial recharge sites identified by geospatial tools in semi-arid region of Anantapur District, Andhra Pradesh, India. Data Brief, 19: 462-474.

Rawat, J. S., Biswas, V. and Kumar, M. 2013. Changes in land use/cover using geospatial techniques: A case study of Ramnagar town area, district Nainital, Uttarakhand, India. The Egyptian Journal of Remote Sensing and Space Science, 16(1): 111-117.

Senthil, S., Arivazhagan, S. and Rangarajan, N. 2013. Remote sensing and GIS applications in environmental science. J. Environ. Nanotechnol, 2: 292-101. doi:10.13074/jent.2013.06.132025. 